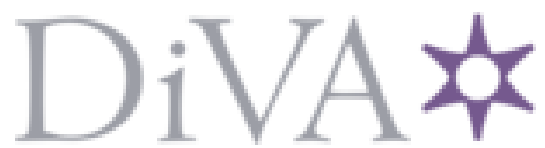

http://www.diva-portal.org

This is the published version of a paper published in International Journal of Electrochemical Science.

Citation for the original published paper (version of record):

Sukhrobov, P., Numonov, S., Mamat, X., Li, Y., Wågberg, T. et al. (2018)

A New Non-Enzymatic Amperometric Sensor Based on Nickel Decorated ZIF-8 Derived

Carbon Nanoframe for the Glucose Determination in Blood Samples

International Journal of Electrochemical Science, 13(7): 6550-6564

https://doi.org/10.20964/2018.07.03

Access to the published version may require subscription.

N.B. When citing this work, cite the original published paper.

Permanent link to this version:

http://urn.kb.se/resolve?urn=urn:nbn:se:umu:diva-151567 


\title{
A New Non-Enzymatic Amperometric Sensor Based on Nickel Decorated ZIF-8 Derived Carbon Nanoframe for the Glucose Determination in Blood Samples
}

\author{
Parviz Sukhrobov ${ }^{1,4}$, Sodik Numonov ${ }^{1,3}$, Xamxikamar Mamat ${ }^{1,}{ }^{*}$, Yongtao Li ${ }^{l}$, \\ Thomas Wågberg, ${ }^{2, *}$ and Guangzhi $\mathrm{Hu}^{1,2, *}$ \\ ${ }^{1}$ Key Laboratory of Chemistry of Plant Resources in Arid Regions, State Key Laboratory Basis of \\ Xinjiang Indigenous Medicinal Plants Resource Utilization, Xinjiang Technical Institute of Physics \\ and Chemistry, Chinese Academy of Science, Urumqi 830011, China. \\ ${ }^{2}$ Department of Physics, Umea University, 90187 Umea, Sweden. \\ ${ }^{3}$ Chinese-Tajik Innovation Center of Natural Products, Dushanbe, 734063, Tajikistan. \\ ${ }^{4}$ University of Chinese Academy of Sciences, Beijing 100049. \\ *E-mail: xamxikmr@ms.xjb.ac.cn (X. Mamat), thomas.wagberg@umu.se (T. Wagberg) and \\ guangzhihu@ms.xjb.ac.cn (G. Hu)
}

doi: $10.20964 / 2018.07 .03$

Received: 13 March 2018 / Accepted: 28 April 2018 / Published: 5 June 2018

\begin{abstract}
The present study demonstrated a highly sensitive non-enzymatic glucose biosensor in real blood samples based on simple evaluated nickel deposited on $\mathrm{N}$-doped porous carbon modified glassy carbon electrode (Ni/NPC/GCE) by applying electrochemical deposition method. The prepared material initially were characterized by cyclic voltammetry, the morphology structure of the as-prepared samples was observed by SEM, and composition, crystals structure of Ni/NPC were identified by SEM mapping and EDS tests. The Ni/NPC/GCE compared with NPC/GCE and NiNPs/GCE performed the best electrocatalytic behavior towards oxidation of glucose in $0.1 \mathrm{M} \mathrm{KOH}$ medium. By applied potential of $+0.6 \mathrm{~V} \mathrm{Ni} / \mathrm{NPC} / \mathrm{GCE}$ showed very high sensitivity of $3753.78 \mu \mathrm{AmM}^{-1} \mathrm{~cm}^{-2}$ in linear range of $1-7940 \mu \mathrm{M}$ with the correlation coefficient of $\mathrm{R}^{2}=0.995$. The linear ranges get views above the concentration up to $7940 \mu \mathrm{M}$ with the detection limit of $0.3 \mu \mathrm{M}$ ( $\mathrm{S} / \mathrm{N}=3)$. Amperometric time responses of prepared electrode towards different glucose concentrations are $0.8-1.3 \mathrm{~s}$. Finally, several positive characteristics such as very high sensitivity, weak working potential, nice anti-interference properties, long stability, good selectivity, and comparison with some other non-enzymatic sensors Ni/NPC/GCE executed high sensitivity, low detection limit and wide linear range to glucose sensing, thus the selected electrode is supplying for future glucose level determination design.
\end{abstract}

Keywords: Nickel deposition, N-doped porous carbon, electrodeposition, glucose biosensor 


\section{FULL TEXT}

(C) 2018 The Authors. Published by ESG (www.electrochemsci.org). This article is an open access article distributed under the terms and conditions of the Creative Commons Attribution license (http://creativecommons.org/licenses/by/4.0/). 